\title{
A Utopia Liberal: Sobre a Autodes- trutividade Intrínseca ao Projeto Político Iluminista
}

\author{
Dax Moraes (UFRJ) \\ daxmoraes@ufrj.br/oejeblik@yahoo.com.br \\ "Mas há maior mal para uma cidade do que aquele que a \\ divide e a torna múltipla em vez de una?" \\ (PLATÃO, A república, V)
}

\begin{abstract}
Resumo: face às distorções encontráveis nos Estados democráticos contemporâneos, com respeito ao modelo liberal em que se fundam, alguns analistas tendem a declarar a falência do modelo, enquanto outros o estimam como ainda não-concluído. Partindo-se da teoria política lockeana, o artigo deverá apontar limitações intrínsecas que, ao invés, impossibilitam mesmo a sustentabilidade de tal modelo a longo prazo.
\end{abstract}

Palavras-chave: teoria liberal lockeana, liberdade de oportunidades, igualdade, isonomia, paradoxos da democracia liberal, desigualdade socioeconômica.

\section{INTRODUCุÃO}

Face às distorções encontráveis nos Estados democráticos contemporâneos, com respeito ao modelo liberal em que se fundam, alguns analistas tendem a declarar a falência do modelo, enquanto outros o estimam como ainda não-concluído. Neste ínterim, pretendo aqui levantar algumas questões relativas às limitações intrínsecas que, ao invés, impossibilitam mesmo a sustentabilidade de tal modelo a longo prazo. Partindo-se da formulação lockeana da democracia liberal, já é possível identificar, em seus fundamentos, a fonte legítima das desigualdades sociais, culturais e econômicas que, hoje, marcam a vida política de diversas nações. A isonomia, que consis- 
te no ponto central de todo o sistema, mostra-se insuficiente à solução do problema, para o que contribui uma "indecisão" teórica que, apesar de poder parecer, à primeira vista, irrelevante, torna-se fatal: Locke não estabelece uma clara relação "hierárquica" ou mesmo "ontológica" entre os princípios de liberdade e de igualdade, caindo em uma circularidade. Em um lugar, os homens são naturalmente livres por serem naturalmente iguais; em outro, naturalmente iguais por serem naturalmente livres.

Em um primeiro movimento da argumentação lockeana pela igualdade radical - leia-se: originária - entre os homens, tem preponderância o discurso sobre a ausência de uma autoridade legítima de uns sobre os outros fundada em privilégios inatos. Sua ética e, posteriormente, sua política e sua "ciência moral" têm dois pilares sobre que se apoiarem: a epistemologia empirista e a unidade biológica distintiva da espécie. Desse modo, rejeitando o inatismo de conteúdos mentais, não há quem possua a graça de conhecer a natureza divina nem quem já nasça provido do direito de governar. Não há, a princípio, uma fé mais legítima do que outra nem um direito natural à autoridade sobre indivíduos da mesma espécie. ${ }^{1}$ Com isso, Locke condena, de um só golpe, a teocracia e a monarquia, bem como a mistura entre religião e política.

Todo o Livro I do Ensaio acerca do entendimento humano é dedicado à refutação da autoridade do conhecimento, de maneira que a nenhum homem deverá caber obrigar outro homem a assumir determinado princípio e rejeitar outro com base no argumento de um acordo universal necessário, seja de ordem especulativa ou prática:

não há nada mais ordinariamente admitido do que a existência de certos princípios, tanto especulativos como práticos (pois referem-se aos dois), com os quais concordam universalmente todos os homens. À vista disso, argumentam que devem ser uniformes às impressões recebidas pelas almas dos homens em seus seres primordiais, que, transportadas por eles ao mundo, 
mostram-se tão necessárias e reais como o são quaisquer de suas faculdades inatas. (LOCKE, 1978b, p. 145)

O (bom) uso da razão, segundo o inatismo, se revelaria quando da admissão de tais idéias e princípios por cada homem, tendendo ao acordo universal, o que Locke rejeita duplamente: primeiro, porque se há "descoberta", não podem ser ditos inatos; segundo, porque tal acordo, de modo algum, verifica-se senão pela educação do espírito em condições comuns (Cf. LOCKE, 1978, p. 145). Já o inatismo das faculdades é e tem de ser admitido por Locke - caso contrário, não haveria garantias para a universalidade da possibilidade de aprender e ter experiências, dogma fundamental sem o qual cairia por terra a criteriologia meritocrática do liberalismo. E daí temos o segundo pilar da defesa da igualdade, que consiste na unidade biológica do ser humano enquanto criatura de Deus e não apenas na unidade psíquica - expressa pela noção de tabula rasa -, que, no contexto de uma teoria empirista, sendo negativa, pouco representa ${ }^{2}$ :

eis que sendo todos os homens obra de um Artífice onipotente e infinitamente sábio - todos servos de senhor soberano único, enviados ao mundo por ordem d'Ele, por cumprir-lhe a missão, são propriedade d'Aquele que os fez, destinados a durar enquanto a Ele aprouver e não a uns e outros; e sendo todos providos de faculdades iguais, compartilhando de uma comunidade de natureza, não há possibilidade de supor-se qualquer subordinação entre os homens que nos autorize a destruir a outrem, como se fôssemos feitos para uso uns dos outros como as ordens inferiores de criaturas são para nós. (LOCKE, 1978b, p. 36)

Não me ocuparei aqui de discutir o caráter temerário de tão fortes afirmações acerca de Deus e de sua relação com o mundo enquanto Criador, nem da liberdade humana em dispor da vida de seres que, embora "inferiores", não devem sua existência ao homem, mas também a Deus. Detendo-me 
estritamente na questão da unidade biológica da espécie, não importando a que eventualmente se deva - com respeito a isto, apenas gostaria de chamar a atenção para o papel fundamental de dogmas correlatos na própria política lockeana, o que já foi discutido em outro lugar. ${ }^{3}$ Basta, então, ter em conta que a igualdade de natureza é tudo o que garante a liberdade natural - na contrapartida, pode-se dispor dos seres inferiores por serem de natureza distinta, não sendo livres perante os homens como estes não o são perante Deus. Acontece que a sociedade civil, onde temos a isonomia e a cidadania, que não estabelecem outra coisa senão a igualdade de condições para todos os homens diferentes entre si, só pode ter lugar pelo consentimento, estimado por Locke como um ato de livre vontade - caso contrário, é ilegítima. Diz ele que todos os homens encontramse no estado de natureza "e nele permanecem até que, pelo próprio consentimento, se tornam membros de alguma sociedade política" (LOCKE, 1978b, p. 39), e também que

a liberdade do homem na sociedade não deve ficar sob qualquer outro poder legislativo senão o que se estabelece por consentimento na comunidade, nem sob o domínio de qualquer vontade ou restrição de qualquer lei senão o que esse poder legislativo promulgar de acordo com o crédito que lhe concedem. (LOCKE, 1978b, p. 43)

Ou seja, fora da sociedade civil, nenhuma outra lei vale senão a da natureza, onde temos desigualdades como entre fortes e fracos, ou astuciosos e tolos, corajosos e covardes, esforçados e preguiçosos, por exemplo, não sendo ilegal que os fortes, ou astuciosos, ou corajosos, ou esforçados prevaleçam sobre fracos, ou tolos, ou covardes, ou preguiçosos. Graças à sociedade, passam a valer as mesmas regras para todos. Mais uma vez, contudo, tais diferenças se manifestam na propriedade de si e do que é produzido exclusivamente pelo indivíduo, direito este garantido tanto no estado de natureza quanto no estado civil, justamente pelo princípio de igualdade natural. Desta vez, igualdade e liberdade aparecem quase indistintas, como se equivalentes: 
Embora a terra e todas as criaturas inferiores sejam comuns a todos os homens, cada homem tem uma propriedade em sua própria pessoa [em sentido estrito, apenas: note-se que não há direito sobre a disposição da vida no sentido de dar-lhe fim pelo suicídio, pois é Deus o senhor da vida, conforme citação acima]; a esta ninguém tem qualquer direito senão ele mesmo. $\mathrm{O}$ trabalho do seu corpo e a obra das suas mãos, pode dizer-se, são propriedade dele. (LOCKE, 1978b, p. 45)

Proprietário do uso de suas forças e, portanto, de seu trabalho e de tudo aquilo a que este se mistura, a produção ou não produção de benefícios é de foro privado. Na mesma medida em que o indivíduo não é obrigado a ceder suas obras, não é sequer obrigado a produzi-las. Qualquer tentativa de se conferir primado à liberdade ou à igualdade, aqui, torna-se bastante embaraçosa.

Tal "indecisão", herdada por nós de maneira acrítica, conduz ao erro de pensarmos ambos os conceitos (liberdade e igualdade) como inerentes um ao outro graças a um terceiro conceito, o de isonomia, que só tem lugar em uma sociedade já constituída. $\bigcirc$ nominalismo lockeano parece ser a fonte do equívoco na medida em que deixa impensada a própria natureza do nomos, donde se pretende mostrar que teremos conseqüências bastante diversas se fundamos o acordo na liberdade natural ou na igualdade natural. Desse modo, embora seu grande alvo seja a igualdade radical de todos os homens enquanto seres racionais, o modelo liberal prevê a progressiva diferenciação dos homens mediante o uso da razão, conduzindo ao privilégio do princípio de liberdade, que se traduz de maneira mais explícita no direito natural à propriedade. É, portanto, no capítulo sobre a propriedade, que consta no Segundo tratado sobre o governo civil, que um conceito fundamental aparece devidamente explicitado de maneira extensiva em sua função, sendo aí que começa a se delinear a "decisão" de Locke. Trata-se da noção de "mérito pessoal". No capítulo seguinte, sobre o pátrio poder, lê-se: 
Embora tenha dito acima (cap. II) que todos os homens são iguais pela natureza, não pretendo suponham que entenda eu toda espécie de igualdade. A idade ou a virtude podem atribuir ao homem justa precedência; a excelência dos dotes e o mérito colocarão outros acima do nível comum; o nascimento pode submeter a alguns e [dispor] alianças e benefícios a outros, para prestar obediência àqueles que a merecem pela natureza, gratidão ou outros motivos; contudo, tudo isso está de acordo com a igualdade em que os homens vivem, relativamente à jurisdição ou domínio de uns sobre os outros, igualdade a que me referia como conveniente ao assunto em foco, consistindo no igual direito de todos os homens à liberdade natural, sem sujeitar-se à vontade ou à autoridade de outrem. (LOCKE, 1978b, p. 55-56, grifo meu)

Deve-se notar que é graças a esta igualdade radical que, como se lê, os homens podem ser ditos naturalmente livres: para pensar e para agir. Eis seu papel fundamental enquanto argumento. Que se recorde ainda que, segundo o empirismo, a virtude e os talentos pessoais dependerão do meio em que se vive e se é educado, donde a "naturalidade" da desigualdade já quando do nascimento do indivíduo, o que significa: a maior ou menor possibilidade de aquisição de mérito, como nos casos de quem já nasce na riqueza ou na miséria. Parece evidente que, se a igualdade implica a liberdade, a liberdade não mais implica a igualdade, pois a liberdade de pensamento e ação permite aos homens se diferenciarem e, a partir do momento em que se associam, tais diferenças deverão ser classificadas conforme o mérito de cada indivíduo. Os homens, então, justa e naturalmente, "não nascem nesse estado de igualdade, muito embora para ele nasçam” (LOCKE, 1978b, p. 56).

A igualdade lockeana não é concebida como algo a ser mantido, mas como critério de legitimação para uma meritocracia, onde os indivíduos não apenas têm igual direito à diferença como também à proporcionalidade das restituições por suas obras. Neste sentido, é ainda pela liberdade que se torna justa a (voluntária) sujeição a tais regras, vistas, positivamente, 
como possibilitadoras de um justo e merecido desenvolvimento pessoal, desde que o mesmo não se configure em prejuízo da sociedade como um todo. Caso não fosse reconhecida a igualdade natural em sua radicalidade, o abismo da incomensurabilidade separaria definitivamente os indivíduos, de modo que jamais poderiam se associar e não se poderia estabelecer critério uniforme para a avaliação de suas obras, senão por pura arbitrariedade, uma vez que mal se poderia afirmar pertencerem a uma mesma espécie - viveríamos ainda no estado de natureza como com relação às criaturas inferiores.

A razão de ser de uma democracia é possibilitar e promover a participação de todo cidadão no processo decisório - partindo-se do princípio de que são todos humanos -, para o que é necessário que todos tenham acesso a certas possibilidades definidas pelos próprios cidadãos, que são a parte interessada. Eles devem ser livres para esta igualdade (agora potencial) de oportunidades. Por um lado, devem ser livres para escolher as possibilidades disponíveis igualmente a todos, mas, por outro, devem antes ser iguais para que possam exercer a liberdade de tal escolha, para que a vontade de cada um tenha o mesmo valor e seja, portanto, igualmente considerada pela sociedade.

O primeiro problema surge com o próprio exercício do poder decisório, onde a minoria, não importa em que número, vê-se compelida a acatar a vontade dominante, uma vez que admitira o critério da "vontade da maioria" como legitimador das convenções, posto que raramente dá-se em sociedade uma vontade única. Pensadores "críticos" como HUME (2000) e ROUSSEAU (2005b) abordaram muito bem esta dificuldade. Se realmente a sociedade funda-se na convenção, toda associação é legítima, sendo sempre o acordo, expresso ou tácito, a instituir o Direito, o que, todavia, não significa que somente a vontade da maioria tenha uma legitimidade natural e não apenas civil. Esta mesma maioria pode-se acreditar obrigada a obedecer e não imaginar outra alternativa, acatando um poder "divino" embora rejeitando suas disposições particulares. Vale dizer ainda: a vontade da maioria se estabelece como petição de princípio, pois constitui, antes, interesse da maioria que 
assim seja. Sequer trata-se de um princípio exclusivo das democracias, pois vale também para uma monarquia absoluta onde a maioria acredite que o poder cabe a um único homem - não é o que ocorria enquanto o Papado e o Absolutismo eram incontestados, e poderiam continuar sendo, pela classe camponesa? Um possível argumento estritamente natural para sustentar esse pretenso princípio como universal seria deriválo da mecânica: dadas forças divergentes em graus, direções e sentidos, prevalece a força maior. Os únicos esclarecimentos possíveis, em uma perspectiva "fisicalista" muito própria da Era Moderna, seriam: 1) o mais forte não anula os menos fortes e, nesse caso, o corpo sobre o qual agem tais forças não se move necessariamente na direção de nenhuma delas em particular; 2) havendo pares de forças antagônicas e iguais agindo simultaneamente sobre um mesmo corpo, o mesmo permanece imóvel. ${ }^{5}$ Desse modo, além de não se tratar, a rigor, de um princípio, continuamos sem possuir um argumento que naturalize a legitimidade da "vontade da maioria", mas apenas a da "vontade geral".

De saída, a representatividade da vontade geral não é absoluta, em sentido próprio, mas sempre relativa, o que é positivo do ponto de vista social, mas também é verdade que, em seguida, a vontade da maioria emperra o progresso pessoal prometido pela democracia, em razão mesmo do caráter impessoal do regime e do poder. Aliás, sequer se deve confundir "vontade geral" - o bem-comum, no sentido de não ser em si mesmo mal para ninguém - e "vontade da maioria", distinção esta que, por si só, exigiria um desenvolvimento à parte. $\mathrm{O}$ que ocorre é o prevalecimento da "vontade da maioria" dentro do âmbito da "vontade geral", onde a primeira exclui as medidas que favoreçam minorias na realização da segunda. Por exemplo, se o bem-estar social constitui a vontade geral, será aprovado o projeto que, ao ver da maioria, melhor atenda a esse interesse comum, que tem a primazia enquanto diretriz das discussões, 
não importando, todavia, que interesses particulares serão satisfeitos ou frustrados por este meio.

O privilégio da convenção sobre a liberdade individual, enquanto possibilita a vida em sociedade, faz com que alguns se submetam ao desígnio de outros. A desigualdade entre aqueles que estão de acordo com a maioria e aqueles que não estão é potencial, sendo que um número indeterminado de alternativas é sempre excluído em benefício de uma única determinação - paradoxo típico da liberdade. Isto, por si só, é motivo de divisão. É necessária uma uniformização de vontades, o que, em parte, é obtido pela cultura e pela instrução como em relação aos anseios de progresso. Por outro lado, a direção do progresso passa a ser motivo de discórdia, e recaímos no problema anterior. Em um sistema livre, isto pode se traduzir em uma pluralidade de partidos que, embora representem uma mesma vontade geral, dificultam sua realização na medida em que pensam em diferentes caminhos ou ordens de prioridade, que não mais se configuram como vontades gerais, consensuais. Embora Rousseau fosse defensor de um pluralismo político, referia-se a uma pluralidade tal que desse conta de toda a diversidade de vontades particulares, de modo que, apenas os interesses comuns prevalecessem - se apenas a vontade geral prevalece, equivale a dizer que cada cidadão deveria ter poder de veto. Diz ele: "para alcançar o verdadeiro enunciado da vontade geral, que não haja no Estado sociedade parcial" - i.e., partidos ou outras associações particulares fundadas segundo interesses de classe - "e que cada cidadão só opine de acordo consigo mesmo" (ROUSSEAU, 2005b, p. 92). Ora, não é o que ocorre: temos, antes, um enfraquecimento generalizado, pois "esquerda", "direita" e "centro" - para não mencionar os inúmeros intermediários - dividem-se internamente em lugar de unir-se em prol de seus interesses comuns. Como então pensamos em interesses comuns da nação se não se definem os interesses comuns de suas classes constitutivas? Não é preciso dizer que a existência de apenas dois ou três partidos apenas 
encobre o problema sem resolvê-lo, enquanto que um sistema unipartidário, em tese, constituiria, na melhor das hipóteses, um autoritarismo. Ora, mas temos em toda democracia uma autoridade da maioria que não deixa de ser, enquanto autoridade, autoritária.

A direção do progresso - definida não mais pela maioria, mas por seus representantes - requer, também, um acordo, e assim a cada passo. Num âmbito geral, é necessária uma visão comum do mundo e de suas possibilidades, e tais possibilidades devem ser, todavia, restritas, o que deve ser obtido pela cultura e pela instrução. A igualdade natural dos homens deve, então, ser mantida a todo custo a fim de que, pelo menos, não se perca a unidade social, e os dilemas da democracia parecem intimamente ligados, sobretudo, à questões relativas à falha nesta "manutenção". Esta falha parece ser inerente ao processo em função do entrave causado pela própria idéia de liberdade para as mesmas possibilidades. Em tese, bastaria que a igualdade de condições fosse mantida, e o restante se auto-ajustaria pelo mérito pessoal, mas eis o grande problema. Poderíamos imaginar que, instaurada a democracia, por uma ação não pouco violenta e autoritária, a todos os cidadãos fosse dada uma igualdade de condições iniciais. A distinção viria pelo uso da razão, ou pela produtividade, no sentido de que cada um fosse capaz de resguardar seu direito à propriedade, cuja preservação, diz Locke, no $\$ 85$ do Segundo tratado, é o "fim principal" da sociedade civil (Cf. LOCKE, 1978b, p. 66). Os melhores resultados obtidos por uns acarretariam o prejuízo de outros, condenados tão-somente por sua própria ineficiência.

Por justo e equânime que isto nos pareça - e Rousseau não o nega, mas apenas ressalta o caráter convencional de toda lei -, constitui a fonte artificial da desigualdade social na medida em que permite às desigualdades naturais se intensificarem exponencialmente!

Estando as coisas nesse estado, teriam assim continuado se os talentos fossem iguais e se, por exemplo, o emprego 
de ferro e a consumação dos alimentos sempre estivessem em exato equilíbrio. Mas a proporção, que nada mantinha, logo se rompeu; os mais fortes realizavam mais trabalho, o mais habilidoso tirava mais partido do seu, o mais engenhoso encontrava meios para abreviar a faina, o lavrador sentia mais necessidade de ferro ou o ferreiro mais necessidade de trigo e, trabalhando igualmente, um ganhava muito enquanto outro tinha dificuldade de viver. Assim, a desigualdade natural insensivelmente se desenvolve junto com a desigualdade de combinação, e as diferenças entre os homens, desenvolvidas pelas diferenças das circunstâncias, se tornam mais sensíveis, mais permanentes em seus efeitos e, em idêntica proporção, começam a influir na sorte dos particulares (ROUSSEAU, 2005a, p. 96).

Serão a indolência e o mau uso da razão as únicas causas do fracasso pessoal quando da igualdade de condições? É necessário que um homem se fortaleça enquanto não precisa regular suas obras pelas de outrem? É manifesto que diferentes indivíduos, ainda que lhes sejam dados os mesmos materiais, não desenvolvem as mesmas técnicas para sua melhoria e, se a liberdade para o desenvolvimento de técnicas não é reprimida, a diferenciação é inevitável. A nível nacional, os bem-sucedidos devem permanecer no ramo e permanecer competindo entre si; os mal-sucedidos devem mudar de atividade ou ser absorvidos como empregados, condição na qual não se desenvolvem, mas apenas recebem instruções e reproduzem fórmulas sem direito à crítica. O que aqui pode parecer justo, deixa de sê-lo quando passamos à geração seguinte. Os respectivos filhos de patrão e empregado não partirão do mesmo ponto; os últimos já estarão em desvantagem em relação aos primeiros.

Ora, quando as heranças cresceram em número e em extensão, a ponto de cobrir todo o solo e tocaram-se umas às outras, uns só puderam prosperar a expensas dos outros, e os supranumerários, que a fraqueza ou a indolência tinham impedido, por seu turno, de as adquirir, tendo-se tornado pobres sem nada ter perdido, porque, tudo mudando à sua volta, 
somente eles não mudaram, viram-se obrigados a receber ou roubar sua subsistência da mão dos ricos. Daí começaram a nascer, segundo os vários caracteres de uns e de outros, a dominação e a servidão, ou a violência e os roubos (ROUSSEAU, 2005a, p. 38).

A conseqüente opressão dos "pequenos" pelos "grandes" só é possibilitada na medida em que ambos se submetem a uma norma comum, são feitos iguais perante uma lei (isonomia). A partir do momento em que reconhecem sua interdependência - pois o "grande", em dado momento, quer produzir mais do que suas capacidades naturais permitem, enquanto que o "pequeno", não possuindo seus próprios meios de produção, deve-se submeter às regras daquele para suprir suas necessidades -, e, portanto, como "iguais", suas diferenças ganham legitimidade, e é justamente neste contexto que podem se intensificar, até sua generalização. Ou seja, quando toda a terra se torna propriedade de alguém, às gerações futuras dos não-proprietários cabe apenas a servidão. É, então, necessário que o Estado forneça a ambos a mesma instrução e condições básicas para o desenvolvimento pessoal no futuro. Algumas gerações adiante, a própria visão de mundo de uma família de tradição assalariada não é a mesma da de uma família de tradição "empreendedora". Esta última tende a pensar uma formação mais completa e diferenciada para sua posteridade, enquanto a primeira, ainda que não conformada com o estritamente necessário à sua subsistência, tende a adquirir uma visão muito mais pragmática, imediatista e utilitarista da própria formação, como mero veículo de inserção social, podendo perder de vista o caráter edificante e abstrato de todo aprimoramento intelectual, cujo lugar na vida prática não teve a oportunidade de reconhecer. ${ }^{6}$

Como solução a tais problemas, não parecem bastar incentivos à iniciativa privada, e isto por duas razões: 10) tratase mesmo da fonte das desigualdades, sobretudo quando detentora de tecnologias; $2^{\circ}$ ) a autonomia profissional, levada a 
extremos, especialmente no setor de serviços e produção de bens artesanais, pode degenerar no esvaziamento dos postos de trabalho tradicionais sem elevação de salários e na queda da produtividade das empresas, o que encarece os produtos e a própria possibilidade de se abrir o próprio negócio algo inviável na medida em que a economia informal torna-se competitiva. Também não parece ser uma solução a elevação do nível escolar quando o mercado não é capaz de absorver tantos profissionais de nível superior. Em um mercado saturado, é inevitável a produção de bens e serviços diferenciados, e esta entrada forçada exige propaganda consumista, inserindo o povo em um círculo vicioso, onde se trabalha excessivamente para se obter aquilo que só existe porque se trabalha excessivamente, e o próprio trabalho em excesso só existe para que todos possam produzir na medida em que isto for possível, inclusive a própria necessidade daquilo que é produzido.

A desigualdade seria pôr fim à economia liberal, fazendo com que toda produção se destinasse ao sustento familiar, apenas o Estado produzisse serviços - inclusa, acima de tudo, a instrução escolar - e somente os impossibilitados para o trabalho recebessem auxílio público. De modo algum atinge esse objetivo a disponibilização de meios igualitários em uma sociedade onde os cidadãos são classificados pelo mérito. No entanto, a própria democracia é um instrumento pelo qual o indivíduo, justamente por seu mérito, tem o que lhe cabe de maneira diferenciada. O dilema reside, pois, no fato de ser dado a todo e qualquer cidadão ser relativamente livre para "inventar" o que lhe cabe, sendo o próprio dinheiro um ótimo exemplo de pérfida invenção.

Por seu empenho na melhoria pessoal, em suas intervenções na natureza, os homens se diferenciam social, cultural e economicamente, de maneira que a distância entre os cidadãos aumenta vertiginosamente a cada geração. Esse processo não pode ser evitado ou detido senão pela intervenção do Estado, que, em sua visão global, não pode agir senão contra o 
princípio fundamental da liberdade individual para produzir e acumular riquezas, que são, por sua vez, contabilizadas como produções e acúmulos para o desenvolvimento da sociedade. Nesse sentido, deve-se lembrar que o homem torna-se provedor de bens e detém o direito de produzir tanto quanto possível, desde que não haja desperdício, pelo que a acumulação de bens imperecíveis, como o dinheiro, desde que, admitidos por convenção, faz da capitalização um direito do cidadão, e isto só é possível porque outros homens poderiam ter produzido e não o fizeram. ${ }^{7}$ Afinal, se não fosse pelo descuido de muitos, não haveria sentido uma produção de excedentes - todos já teriam tudo de que necessitassem -, o comércio se restringiria a trocas de mercadorias, todos teriam terras e a produção de bens supérfluos seria mero fruto da ociosidade, sem muito valor ou mesmo valor algum, ao invés de meio de inserção no mercado de trabalho. Ou seja, a conseqüência da teoria liberal, em sua gênese, é que, se todo homem tivesse se empenhado na conservação do próprio sustento, não haveria espaço para as desigualdades, o que faz com que as classes menos favorecidas sejam herdeiras de homens que não agiram racionalmente, havendo legitimado, por esta indolência e oportunismo, a crescente desigualdade social.

\begin{abstract}
In view of misguidance found in democratic States concerning their grounding liberal model, some analysts are inclined to declare the bankrupt of liberalism, as well there are others who consider it not yet achieved. This paper aims to indicate in Locke's political theory some intrinsic limitations of this model itself that has as result its very non-sustainability at long date.
\end{abstract}

Key-words: Locke's liberal theory, free opportunitie, equality and isonomy, paradoxes in liberal democracy, socioeconomic inequality. 


\section{NOTAS}

1 Estas afirmações se desdobram ambas na problemática da tolerância, seja ela religiosa ou política. No primeiro caso, Locke reconhecerá formas intoleráveis de crença religiosa, que corresponderão àquelas que infringem os direitos naturais fundamentais à vida e à propriedade, classe em que se enquadrariam os terroristas fundamentalistas (LOCKE, 1978a. p. 22-24). A estas formas de "falsa religião", Locke acrescenta o ateísmo (!), e isto por razões que o espaço disponível não permite serem aqui pormenorizadas, embora de grande relevância. Quanto à autoridade e à tolerabilidade políticas, Locke as coloca a cargo das convenções sociais que estabelecem as leis e os costumes, donde a rejeição ao ceticismo moral. A problematização destes temas, bem como de outros aqui abordados, recebe tratamento especial em meu artigo: "Omnis affirmatio est negatio" ou A intolerante tolerância: paradoxo ou engodo da democracia (MORAES, 2003).

2 Um exemplo esclarecedor: a ausência de idéias inatas nos animais inferiores não basta para igualá-los aos humanos, que se distinguem deles por suas faculdades positivas de cognição de que não são dotados os primeiros.

3 Sobre isto, ver. MORAES (2003, p. 178-182).

4 Sobre a legitimidade da propriedade pelo trabalho, ver também ROUSSEAU (2005a, p. 95-96).

5 De acordo com esta metáfora "fisicalista", substituindo-se os termos força e corpo, respectivamente, por vontade e sociedade, concluímos, contra todo autoritatismo: de "1", que a vontade geral tende para a maioria, mas não corresponde necessariamente a nenhuma vontade em particular, 
nem à sua soma; de "2", que é necessária uma diversidade de forças diferenciadas para que haja mobilidade social ao invés de estagnação. Não deixa de ser um bom apelo naturalista, caso se lhe dê algum valor.

6 Deve-se reconhecer as exceções: filhos de famílias abastadas podem negligenciar a necessidade de esforço para a conservação do patrimônio recebido sem trabalho, tornando-se perdulários, enquanto os filhos de famílias extremamente pobres podem dar extremo valor ao crescimento espiritual. Todavia, isto parece depender muito de como o ideal de progresso pessoal é assimilado por cada um. Refiro-me, portanto, não a algo de absoluto - tal consistiria em preconceito injustificável! -, mas a uma tendência produzida pelo próprio desenvolvimentismo em vigor, segundo o qual se questiona se os parâmetros mínimos garantidos pelo Estado são eficazes em uma sociedade movida pela maximização de resultados.

7 Sobre isto, vale conferir todo o capítulo do Segundo tratado de Locke dedicado à propriedade.

\section{REFERÊNCIAS}

HUME, David. Ensaios morais, políticos e literários. Trad. João Paulo Gomes Monteiro e Armando Mora d'Oliveira. São Paulo: Nova Cultural, 2000. p. 155-350. (Coleção Os Pensadores)

LOCKE, John. Carta acerca da tolerância. Trad. Anoar Aiex. São Paulo: Abril Cultural, 1978a. p. 1-29. (Coleção Os Pensadores). 
. Segundo tratado sobre o governo: ensaio relativo à verdadeira origem, extensão e objetivo do governo civil. Trad. E. Jacy Monteiro. São Paulo: Abril Cultural, 1978b. p. 31-131. (Coleção Os Pensadores).

. Ensaio acerca do entendimento humano. Trad. Anoar Aiex. São Paulo: Abril Cultural, 1978c. p. 133-344. (Coleção Os Pensadores).

MORAES, Dax. "Omnis affirmatio est negatio" ou A intolerante tolerância: paradoxo ou engodo da democracia. Ethica Cadernos acadêmicos, Revista do Programa de Pós-Graduação em Filosofia da Universidade Gama Filho (UGF), Rio de Janeiro, v. 10, n. 1 e 2, p. 159-190, 2003.

ROUSSEAU, J.-J. Do contrato social: ou princípios do direito político. Vol. I, Trad. Lourdes Santos Machado. São Paulo: Nova Cultural, 2005a. p. 27-243. (Coleção Os Pensadores).

. Discurso sobre a origem e os fundamentos da desigualdade entre os homens. Vol. II. Trad. Lourdes Santos Machado. São Paulo: Nova Cultural, 2005b. p. 5-163. (Coleção Os Pensadores). 